
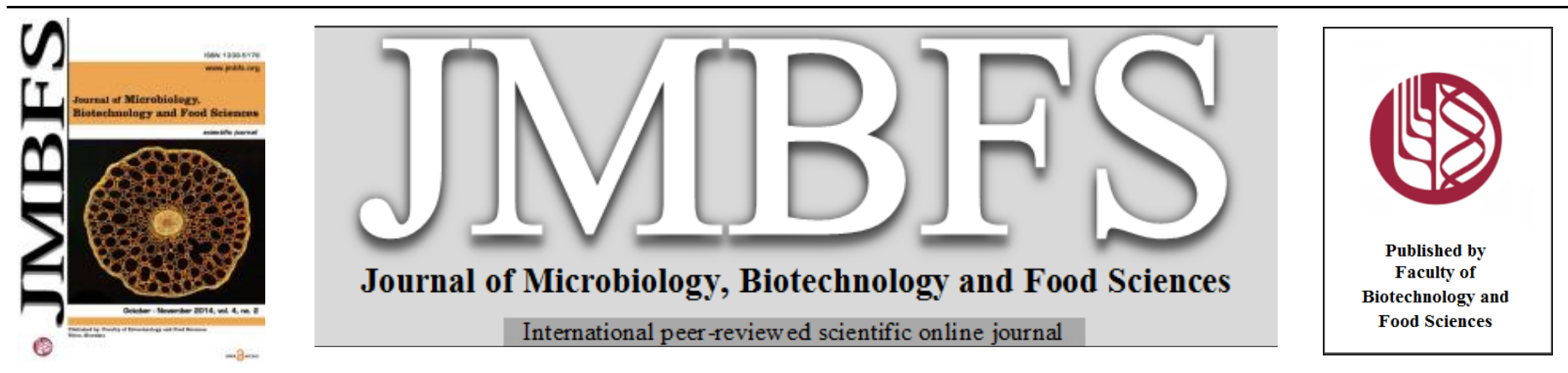

\title{
IN VITRO PRODUCTION OF MICRORHIZOMES IN GINGER (ZINGIBER OFFICINALE ROSCO)
}

\author{
Mohamed Abbas ${ }^{* 1}$, Usama Aly ${ }^{2}$,Hussein Taha ${ }^{2}$, and El-Sayed Gaber ${ }^{1}$ \\ Address(es): \\ ${ }^{1}$ Cairo University, Institute of African Research and Studies, Department of Natural Resources, El Gamma St.,12613, Cairo, Egypt \\ ${ }^{2}$ Plant Biotechnology Department, Genetic Engineering and Biotechnology Division, National Research Centre, El Buhouth St., 12311, Dokki, Cairo, Egypt
}

*Corresponding author: msaelsarawy@yahoo.com

doi: 10.15414/jmbfs.2014.4.2.142-148

\section{ARTICLE INFO}

Received 10. 6. 2014

Revised 26. 8. 2014

Accepted 26. 8. 2014

Published 1. 10. 2014

Regular article

OPEN $\partial_{\text {ACCESS }}$

\section{ABSTRACT}

The present investigation was carried out to highlight an effective protocol for in vitro production of ginger microrhizomes. Microrhizomes were induced at the base of the in vitro derived shoots upon transfer to MS medium containing various concentrations of (30, 60 and $90 \mathrm{~g} / \mathrm{L}$ ), BAP: 6-benzylaminopurine $(3,6$ and $9 \mathrm{mg} / \mathrm{L}$ ) and grown under varying photoperiodism in addition to the MS medium supplemented with $9 \mathrm{mg} / \mathrm{L} \mathrm{BAP}$ and $60-90 \mathrm{~g} / \mathrm{L}$ sucrose under $16-\mathrm{h}$ photoperiod within 10 weeks of cultivation were the best conditions for microrhizomes induction. Ginger microrhizomes formation in vitro was found to be controlled by many factors, including the concentrations of BAP and sucrose as well as photoperiodism during culturing period.

Keywords: Ginger, Zingiber officinale, Ginger, Photoperiodism, Sucrose, BAP and Microrhizomes

\section{INTRODUCTION}

Ginger (Zingiber officinale Rosco) belonging to the family Zingiberaceae is one of the world's most important spices and produces a pungent, aromatic rhizome that is valuable all over the world not only as a spice but also as herbal medicine for its health promoting properties. Based on several reports (Rout et al., 2001, Guo and Zhang, 2005, Ma and Gang, 2006, Guo et al., 2007, Guan et al., 2008 and Zheng et al., 2008) ginger, is constrained severely can summarized as following: (1) ginger normally propagates by its rhizome, with a low proliferation rate, and the reproducing part (the rhizome) is also the economically used part of the ginger plant, which restricts the availability of ginger seeds needed for cultivation, (2) easily infected by soil-born pathogens such as bacterial wilt (Pseudomonas solanacearum), soft rot (Pythium aphanidermatum), and nematodes (Meloidogyne spp.), which cause heavy losses in yield.

Ginger micro-rhizomes were induced by few authors i.e. Sharma and Singh (1995) who found that, MS medium supplemented with $8 \mathrm{mg} / \mathrm{L}$ BAP produced the microrhizomes. However, Bhat et al. (1994) and Zheng et al. (2008) they indicated that, ginger rhizome formation in vitro is affected by many factors, including photoperiod, mineral nutrition, culture methods (liquid or solid culture), and carbon source. In addition, Rout et al. (2001) concluded that, the indication under 24-h photoperiod helped in production of ginger rhizomes and Roh et al. (1996) who reported that young plantlets of ginger formed rhizomes when cultured on MS medium containing sucrose $90 \mathrm{~g} / \mathrm{L}$. on other hand, Archana et al. (2013) developed ginger microrhizome protocol for large scale production using MS medium supplemented with externally added $\mathrm{NH}_{4} \mathrm{NO}_{3}$

The advantages of in vitro micro-rhizomes production of ginger can be summarized in the following points; (i) microrhizomes production in vitro in a sterile conditions during any season, (ii) using microrhizomes has commercial potential for micro-propagation, (iii) microrhizomes can be used as pathogen free seed rhizomes specially in regions with high disease pressures and (iv) microrhizomes are easily storage, transport and can used in germplasm conservation. Therefore, the present investigation was carried out to highlight an effective, reliable and reproducible protocol for in vitro production of ginger microrhizomes.

\section{MATERIALS AND METHODS}

In vitro micro-rhizomes production

Four to five centimeter long of the in vitro derived shootlets (Abbas, et al. 2011) were separated from the initial culture and transferred to solid MS medium (Murashige and Skoog 1962 ) supplemented with different concentrations of sucrose $(30,60$ and $90 \mathrm{~g} / \mathrm{L})$, BAP $(3,6$ and $9 \mathrm{mg} / \mathrm{L})$ and $0.7 \%$ agar. Each treatment consisted of 5 replicates in addition to the control treatment as follows:

\begin{tabular}{llcc} 
HC & \multicolumn{2}{c}{$\begin{array}{c}\text { Sucrose }(\mathbf{g} / \mathbf{L}) \\
\text { MS basal free sucrose }\end{array}$} & Growth regulato \\
H1 & MS + & $30+$ & $3 \mathrm{mg} / \mathrm{L} \mathrm{BAP}$ \\
H2 & MS + & $30+$ & $6 \mathrm{mg} / \mathrm{L} \mathrm{BAP}$ \\
H3 & MS + & $30+$ & $9 \mathrm{mg} / \mathrm{L} \mathrm{BAP}$ \\
H4 & MS + & $60+$ & $3 \mathrm{mg} / \mathrm{L} \mathrm{BAP}$ \\
H5 & MS + & $60+$ & $6 \mathrm{mg} / \mathrm{L} \mathrm{BAP}$ \\
H6 & MS + & $60+$ & $9 \mathrm{mg} / \mathrm{L} \mathrm{BAP}$ \\
H7 & MS + & $90+$ & $3 \mathrm{mg} / \mathrm{L} \mathrm{BAP}$ \\
H8 & MS + & $90+$ & $6 \mathrm{mg} / \mathrm{L} \mathrm{BAP}$ \\
H9 & MS + & $90+$ & $9 \mathrm{mg} / \mathrm{L} \mathrm{BAP}$
\end{tabular}

The solidified MS cultures media were divided into two groups the first group was incubated under a 16-h/day photoperiod at intensity of $3000 \mathrm{Lux}$ from cool light fluorescent lamps for 10 weeks (two subcultures). The second was maintained in darkness conditions for 10 weeks (two subcultures). All cultures were incubated at $25 \pm 1^{\circ} \mathrm{C}$. For each combination of previous media, three experiments were carried out consisting of 30 treatments for each 5 replicates under light and darkness conditions. The following measurements were considered as follow: number of rhizomes formation, number of buds, rhizomes fresh weight / jar (g), rhizomes dry weight / jar (g), dry matter content (\%) the percentage of dry matter contents was estimated according the following equation: dry matter content $(\%)=($ dry weight $\mathrm{x} 100) /$ fresh weight, average number of buds/rhizome was estimated as follows: the total number of buds divided by the total number of rhizomes formation and average weight of microrhizome ( $\mathrm{g}$ ) was estimated as follows: the total rhizomes fresh weight (g) divided by the total number of rhizomes formation.

\section{Statistical analysis}

The resulted data were subjected to statistical analysis, employing F-test for significance at $P \leq 0.05$ using MSTAT C program and computing of "Least Significant Difference (L.S.D.)" values to separate means in different statistical groups according to described method by Gomez and Gomez (1984). 


\section{RESULTS AND DISCUSSION}

\section{Number of rhizomes formation}

Data tabulated in Table (1) and illustrated in Figures (1,2 and 3) showed that, the overall results of this experiment. The effects of three different concentrations of sucrose and $\mathrm{BAP}$ on microrhizomes produced were tested under light (16-h/day) and darkness (24-h/day). Basal part of the shoots started swelling within 1- to 2months-old culture, which was a signal for a process of rhizomes formation then rhizomes had characteristic yellow-orange color and possessed a fresh aromatic odor when cut. Lineally functional storage organs, rhizomes, had formed in vitro. Generally, significant difference was observed in number of rhizomes/ concentrations of sucrose, BAP and photoperiodism incubation.

Initially, induction of rhizomes was influenced significantly by photoperiodism exposure. However, under both photoperiodism conditions in continuous darkness, the lower number of rhizomes initiation was recorded comparing with light condition.

Photoperiod was reported to play a key role in induction of in vitro storage organs by Nayak (2000) who found that, 8-h photoperiod was the optimum for induction of microrhizomes of Curcuma aromatica. Moreover, Rout et al. (2001) concluded that, the indication under 24-h photoperiod helped in production of maximum number of ginger rhizomes as compared to 8- or 16-h photoperiod. In addition, Zheng et al. (2008) cleared that, the best condition for maximum ginger microrhizome production, was incubation of cultures under complete illumination of 24-h continuous light.

On other hand, Shirgurkar et al. (2001) found that incubation under dark at $25 \pm 1^{\circ} \mathrm{C}$ was optimal condition for microrhizome production of Curcuma longa

L. (Zingeberaceae). However, Tyagi et al. (2006) indicated that, rhizome formation occurred under all the three treatments of light, and no significant effect of light treatments (16-h, 24-h, and darkness) was observed on induction of rhizomes in ginger.

Impact of sucrose on number of rhizomes formation: the in vitro rhizome formation was significantly influenced by sucrose level (Table 1). Further, it could be noticed that when sucrose concentration was low in rhizome induction medium the number of rhizomes will be decreased under light condition. High amount of sucrose promoted formation a high number of rhizome formation. In this respect, the highest number of rhizomes production was recorded with MS medium treated with 90 and $30 \mathrm{~g} / \mathrm{l}$ sucrose under light and darkness conditions, respectively. The obtained data suggest a simple direct relationship between carbohydrate availability and rhizomes formation. Superficially, the presence of adequate sugar appears to trigger rhizomes genesis. The enhanced rate of in vitro microrhizome formation with increasing concentration of sucrose may be attributed to the presence of high carbon energy in sucrose since rhizomes mostly contain carbohydrates and sucrose (Nayak, 2000). The stimulation of tuber, bulbs and rhizomes formation by increasing sucrose concentrations in the medium has been reported by Rout $\boldsymbol{e t}$ al. (2001) they cleared that, at a higher concentration of sucrose (3-8\%) there was an increase in the percentage of rhizome formation of ginger and number of rhizomes per plant. Further, the maximum rhizome formation was observed in medium containing 6-8\% of sucrose. Furthermore, Martin (2003) found that, the bulbs were formed at the base of each shoot on medium supplemented with 6 or $8 \%$ sucrose exhibited an increased tendency to develop into rhizomes of Ipsea Malabarica. Moreover, Ebrahim (2004) cleared that, superior Calla rhizome formation was obtained on MS-basal medium containing sucrose $(70 \mathrm{~g} / \mathrm{L})$.

Table 1 Effect of MS medium supplemented with different concentrations of sucrose and BAP on number of rhizomes formation, number of buds, fresh and dry weights (g/jar) of Zingiber officinale after 10 weeks of cultivation under light $(\mathrm{L})$ or darkness (D) conditions at $25 \pm 1{ }^{\circ} \mathrm{C}$.

\begin{tabular}{|c|c|c|c|c|c|c|c|c|c|c|}
\hline \multirow[t]{2}{*}{ Code } & \multirow[t]{2}{*}{ Sucrose $(g / L)$} & \multirow{2}{*}{$\begin{array}{c}\text { BAP } \\
(\mathrm{mg} / \mathrm{L})\end{array}$} & \multicolumn{2}{|c|}{ Number of rhizomes } & \multicolumn{2}{|c|}{ Number of buds } & \multicolumn{2}{|c|}{$\begin{array}{c}\text { Fresh weight } \\
\text { (g/jar) }\end{array}$} & \multicolumn{2}{|c|}{$\begin{array}{c}\text { Dry weight } \\
\text { (g/jar) }\end{array}$} \\
\hline & & & $\mathbf{L}$ & D & $\mathbf{L}$ & $\mathbf{D}$ & $\mathbf{L}$ & D & $\mathbf{L}$ & D \\
\hline$\overline{\mathrm{HC}}$ & \multicolumn{2}{|c|}{ MS basal free sucrose } & 0.00 & 0.00 & 0.00 & 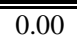 & 0.00 & 0.00 & 0.00 & 0.000 \\
\hline H1 & 30 & 3 & 3.33 & 4.67 & 3.67 & 5.67 & 1.03 & 0.66 & 0.06 & 0.069 \\
\hline H2 & 30 & 6 & 9.67 & 13.67 & 33.67 & 39.33 & 5.07 & 4.90 & 0.27 & 0.300 \\
\hline $\mathbf{H 3}$ & 30 & 9 & 4.33 & 7.67 & 37.33 & 50.67 & 7.48 & 5.80 & 0.37 & 0.291 \\
\hline H4 & 60 & 3 & 9.67 & 9.00 & 34.33 & 32.00 & 5.73 & 3.40 & 0.55 & 0.412 \\
\hline H5 & 60 & 6 & 7.67 & 9.00 & 51.33 & 42.33 & 6.99 & 5.14 & 0.64 & 0.497 \\
\hline H6 & 60 & 9 & 10.00 & 4.67 & 66.00 & 14.00 & 9.45 & 1.58 & 0.74 & 0.149 \\
\hline H7 & 90 & 3 & 14.00 & 10.67 & 51.33 & 37.00 & 5.33 & 4.19 & 0.92 & 0.712 \\
\hline H8 & 90 & 6 & 14.67 & 11.33 & 43.00 & 31.67 & 4.31 & 3.32 & 0.93 & 0.564 \\
\hline H9 & 90 & 9 & 15.33 & 11.33 & 51.67 & 34.33 & 7.20 & 3.87 & 1.01 & 0.688 \\
\hline \multirow{2}{*}{$\mathbf{L S D}_{0.05}$} & & A, B & 0.86 & 1.33 & 1.60 & 1.62 & 0.13 & 0.32 & 0.03 & 0.011 \\
\hline & & AB & 1.49 & 2.30 & 2.78 & 2.80 & 0.23 & 0.05 & 0.05 & 0.020 \\
\hline
\end{tabular}

Legend: A - Concentration of sucrose, B - BAP levels, AB - Interaction

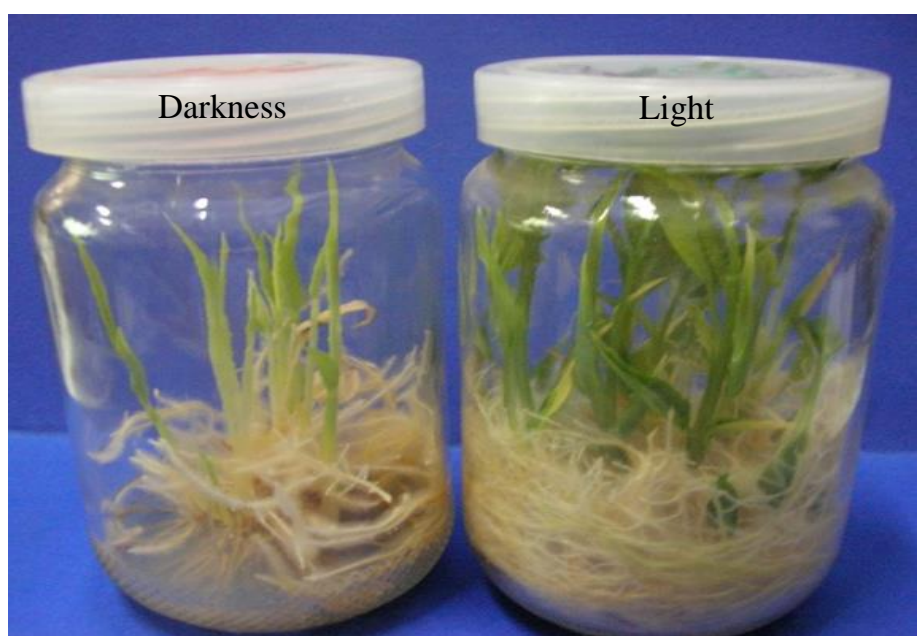

Figure 1 Morphological characters of Zingiber officinale inductive microrhizomes plantlets growing on MS medium fortified with $60 \mathrm{~g} / 1$ sucrose and 9 $\mathrm{mg} / \mathrm{l} \mathrm{BAP}$ after 10 weeks of cultivation under light and darkness conditions at $25 \pm 1^{\circ} \mathrm{C}$.

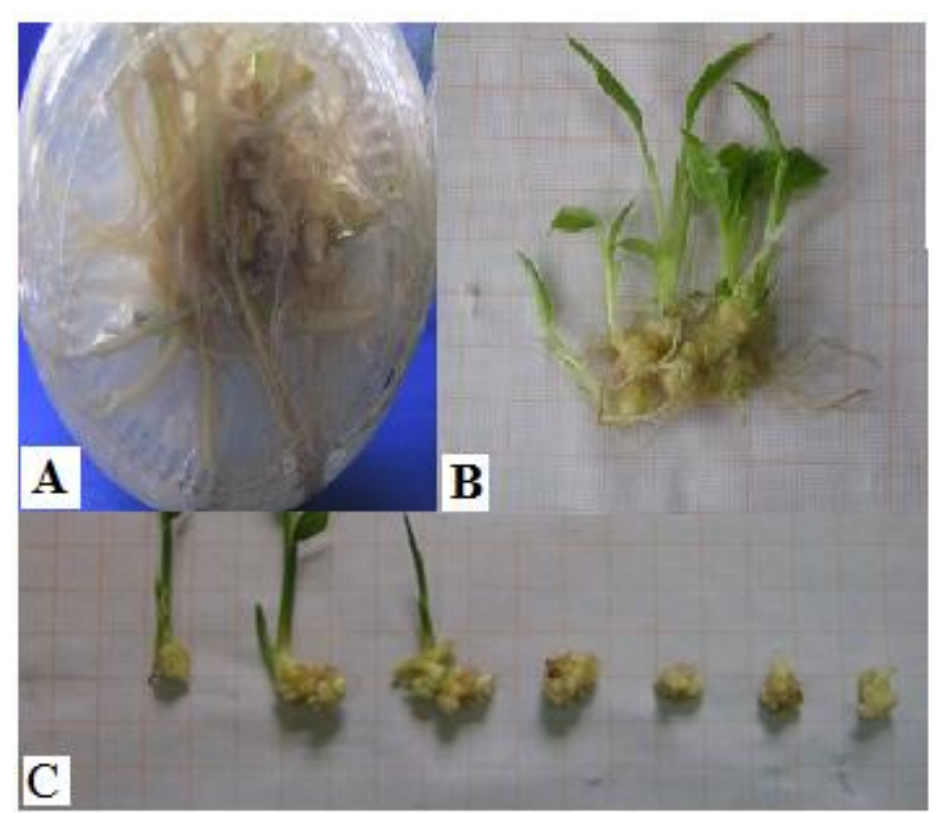

Figure 2 In vitro production of Zingiber officinale microrhizomes. A\&B: represent shoots showing swollen bases on microrhizome induction medium and C: Microrhizomes of different sizes harvested after 10 weeks of incubation under light condition at $25 \pm 1^{\circ} \mathrm{C}$. 


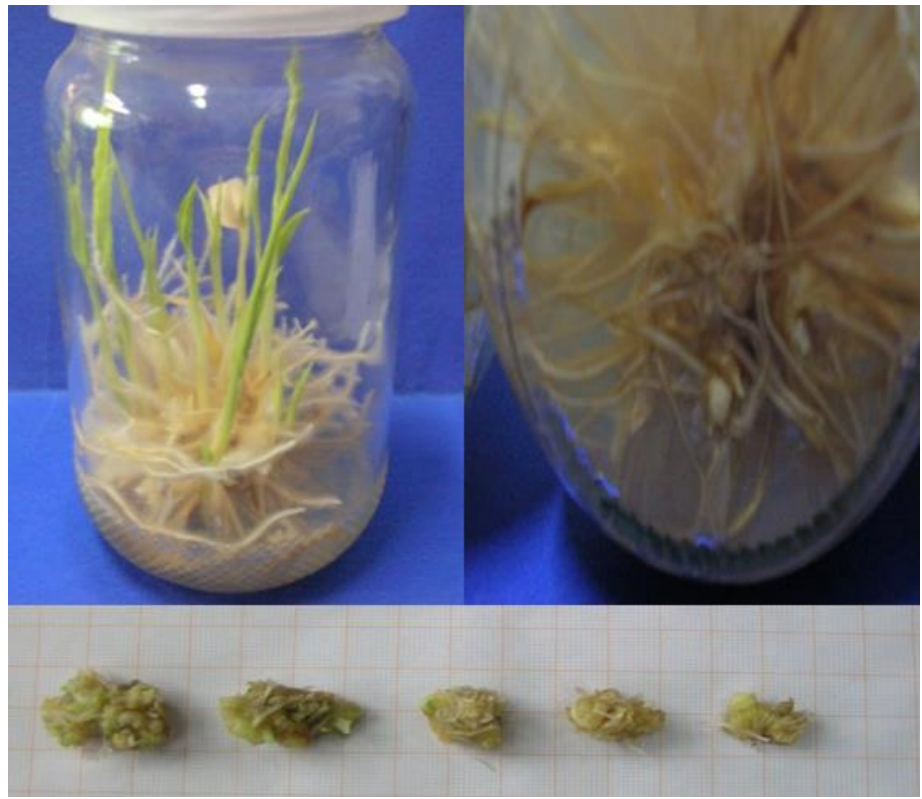

Figure 3 In vitro production of Zingiber officinale microrhizomes. A: Plantlet, B: represent shoots showing swollen bases on microrhizome induction medium and $\mathbf{C}$ : Microrhizomes of different sizes harvested after 10 weeks of incubation under darkness condition at $25 \pm 1^{\circ} \mathrm{C}$.

In addition, Chirangini and Sharma (2005) examined induction of microrhizome in Zingiber cassumunar and found that the best responses in terms of microrhizomes number (up to 6 microrhizomes per culture tube) were obtained with MS media supplemented with 7 and 9\% sucrose. Whereas, Jo et al. (2009) cleared that, sucrose may be essential as an osmoticum, as an energy source and at higher concentration it may have a role as a signal for microtubers formation. Impact of cytokinin level on number of rhizomes: the BAP level had significantly influenced the in vitro number of rhizomes formation (Table 1). Data displayed that MS medium supplemented with $9 \mathrm{mg} / \mathrm{l}$ BAP indicated the best results of in vitro rhizomes formation under light conditions while supplementation of MS medium with $6 \mathrm{mg} / \mathrm{l} \mathrm{BAP}$ was more favorable for microrhizomes induction under darkness.

The effect of cytokinin level on growth and development in vitro rhizomes was supported by Bhat et al. (1994) and Zheng $\boldsymbol{e t}$ al. (2008) they indicated that, ginger rhizome formation in vitro is affected by many factors, including photoperiod, mineral nutrition, culture methods (liquid or solid culture), and carbon source. In addition, Kapoor and Rao (2006) they indicated that, plant growth regulators are known to affect normal shoot organogenesis, which can be modified to generate tubers, rhizomes and corms.

Figure (4) show that the significant interaction between sucrose, BAP and photoperiodism on number of rhizomes produced per culture. Cultures treated with $90 \mathrm{~g} / \mathrm{L}$ sucrose and 3, 6 and $9 \mathrm{~m} / \mathrm{L}$ BAP under light conditions gave the highest number of micro-rhizomes $14,14.67$ and 15.33, respectively. While cultures incubated under darkness and treated with $30 \mathrm{~g} / \mathrm{L}$ sucrose and $6 \mathrm{~m} / \mathrm{L}$ BAP gave the highest number of rhizomes (13.67) without significant differences between them.

\section{Number of buds formation}

Sucrose, BAP and photoperiodism treatments significantly affected on number of buds formation at the 5\% level. The effects of light and darkness conditions on number of buds formation of ginger cultures incubation at $25^{\circ} \mathrm{C}$ were investigated. The obtained results are presented in Table (1) and Figures (1, 2 and 3 ), which showed that, the number of buds formation under 16-h photoperiod was significantly better than that produced under darkness. Similarly, Mantell and Hugo (1989) who indicated that, photoperiod had a strong effect on microtuber induction, with 8-h photoperiods being more effective for higher microtuber induction frequencies in Dioscorea alata and D. bulbifera. In addition, Pruski et al. (2002) indicated that, eight hours photoperiod was far the best treatment for the production of high-quality uniform microtubers of potato.

Concerning, the effect of sucrose concentrations on in vitro micro-rhizomes production: In order to develop an optimized standard protocol, effects of different concentrations of sucrose were investigated under fully darkness and 16-h photoperiod (Table 1). It was observed that sucrose plays a significant role in number of buds formation however; the moderate concentration of sucrose $(60$ $\mathrm{g} / \mathrm{L}$ ) produced the maximum number of buds under 16-h photoperiod. While, the maximum number of buds formation was observed with low or high concentrations of sucrose (30 and $90 \mathrm{~g} / \mathrm{L}$ ) under darkness condition. These results were in accordance with those obtained by Roh $\boldsymbol{e t}$ al. (1996) who reported that young plantlets of Zingiber officinale Rosco formed rhizomes when cultured on MS medium containing sucrose $90 \mathrm{~g} / \mathrm{L}$.

Regarding, the effects of the presence of a different levels of BAP (3, 6 and 9 $\mathrm{m} / \mathrm{L}$ ) on number of buds formation were investigated and the obtained results are presented in Table (1). Among the different concentrations of BAP, MS medium supplemented with $9 \mathrm{mg} / \mathrm{L}$ BAP was exhibited a better response in terms of mean number of buds formation. However, the average number of buds formation was 30,43 and 52 buds from 3, 6 and $9 \mathrm{mg} / \mathrm{L}$ BAP, respectively. These results are in accordance with those obtained by Sharma and Singh (1995) who found that MS medium supplemented with $8 \mathrm{mg} / \mathrm{L}$ BAP produced the maximum buds number of microrhizomes in ginger. On other hand, Kapoor and Rao (2006) found that, increase in the concentration of BAP led to a reduction in percentage of cultures forming rhizomes in Bambusa bambos cultures

With respect to the influences of photoperiodism, sucrose, and BAP on number of buds formation, the relative effects of these characters are summarized in Figure (5). The maximum number of buds formation was produced from MS medium included $60 \mathrm{~g} / \mathrm{l}$ sucrose and $9 \mathrm{mg} / \mathrm{l}$ BAP under light condition with significant difference comparing with other treatments.

\section{Rhizomes fresh weight $(\mathrm{g})$}

All tested factors, sucrose, BAP and photoperiodism significantly affected on rhizome fresh weights. The difference between two photoperiodism treatments on rhizome fresh weights was significant. However, careful observations of data in Table (1) and Figures (1, 2 and 3) clearly show that, the highest rhizome fresh weights was obtained in cultures incubated under light condition 16-h/day with average 5.8 (g/jar). While, incubation under darkness condition produce lowest rhizome fresh weights with average yield 3.7 ( $\mathrm{g} / \mathrm{j}$ ar) that may be due to the incubation under light condition the increase in the productivity of the plants can be attributed to increase in the photosynthetic rate comparing with darkness conditions that caused increasing in amounts of produced energy in storage part (rhizome). In contrary, the incubation under darkness conditions; the respiration rate was higher than photosynthesis rate and this destroyed the storage energy in plant (Figure 5). These results are in harmony with those reported by Slimmon $\boldsymbol{e}$ al. (1989) they found that, photosynthate translocation to a microtuber, which acts as a sink, could account for the increase in fresh weight of microtubers produced under the light regime. Moreover, Jean and Cappadocia (1992) found that, the largest Dioscorea alata tuber biomass was formed on MS medium under 8-h photoperiod. In addition, Das et al. (1999) reported that, the formation of tuber in vitro was attributed to active photosynthesis, which supplied additional energy necessary for tubers formation.

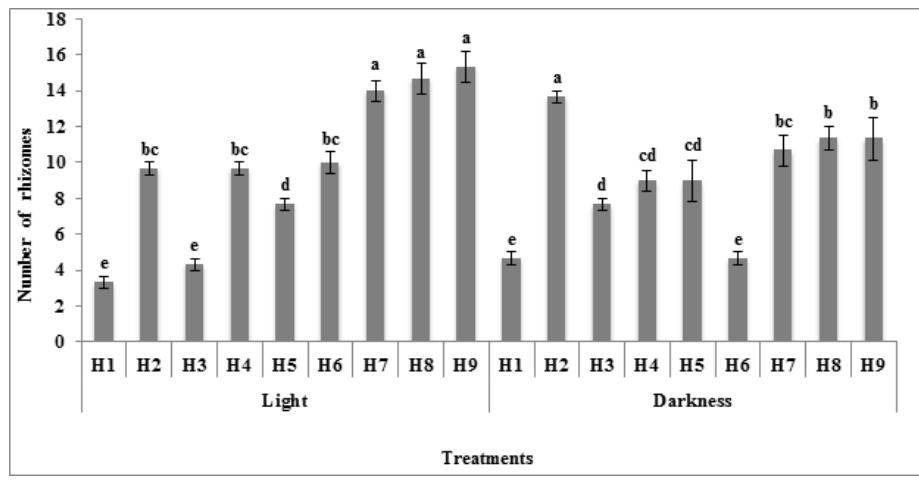

Figure 4 Influence of the interaction between sucrose, BAP and photoperiodism on number of rhizomes formation. Error bars are \pm SE. Treatments that are not significantly different at the $5 \%$ level are indicated by the same letters.

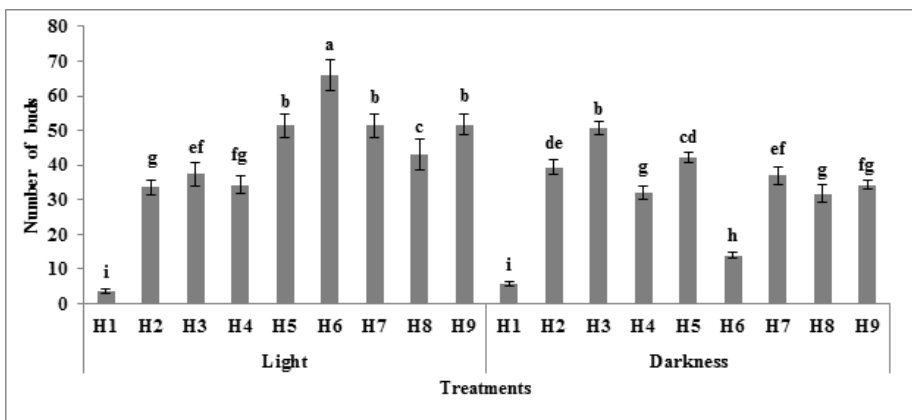

Figure 5 Influence of the interaction between sucrose, BAP and photoperiodism on number of buds formation. Error bars are \pm SE. Treatments that are not significantly different at the $5 \%$ level are indicated by the same letters.

Concerning the influences of sucrose on rhizomes fresh weight: sucrose concentrations were significantly different $(\mathrm{P} \leq 0.05)$ among the different 
treatments. It is evident from the obtained data (Table 1) that, cultures incubated under light conditions were more benefit of presence of sucrose in culture medium comparing with cultures incubated under fully dark condition. However, the moderate and high concentrations of sucrose $(60-90 \mathrm{~g} / \mathrm{l})$ produced the highes mass production of rhizomes. In contrast, the limited effects of sucrose under darkness condition may be due to utilizations of sucrose in photosynthesis processes to produce energy by green plantlets under light conditions.

The obtained results of the present investigation support to Lauzer et al. (1992) they reported that, in Dioscorea mangenotiana, no tubers were obtained on media containing either 20 or $80 \mathrm{~g} / 1$ sucrose, under all the light conditions tested. On media containing 40-60g/L sucrose in vitro produced the biggest tuber. However, Islam et al. (2004) found that, nine percent sucrose was found to be the mos suitable for microrhizome production and gave the largest microrhizome of Curcuma longa in vitro. In addition, Chithra et al. (2005) found that, sucrose at 6-8\% added to the optimal medium was most favorable for rhizome formation of Kaempferia galangal and the rhizomes were $>100 \mathrm{mg}$ after 70 days of culture. Moreover, Ondo Ovono et al. (2009) reported that, for mass production of microtubers in yam, the bigger tubers were obtained on high sucrose media which could be containing more carbohydrate reserves

The influences of BAP at different concentrations on rhizome fresh weight are shown in Table (1). Overall results cleared that, there are a positive relationship between increasing of BAP concentrations $(3,6$ to $9 \mathrm{mg} / \mathrm{L})$ and rhizome fresh weight under light conditions with average $4.03,5.45$ and $8.04 \mathrm{~g}$, respectively. A the contrary, no relationship was observed between increasing of BAP concentrations (3, 6 to $9 \mathrm{mg} / \mathrm{L})$ and fresh rhizome weights under fully darkness condition with average of $2.75,4.45$ and $3.75 \mathrm{~g}$, respectively. Similar observations had been described by Medina et al. (2009) who reported that, BAP addition to the culture medium promoted root tubers formation in Habenaria bractescens and they found that MS medium with $87.6 \mathrm{mM}$ sucrose plus $4.4 \mu \mathrm{M}$ BAP was one of the most effective for stimulating root tubers.

On the other hand, Ghosh et al. (2007) indicated that, cytokinins were showed strong inhibitory effect on secondary tuber production; BA showed inhibitory effect and Kin failed to promote tuber growth of Gloriosa superb. In additions, Sarkar et al. (2006) indicated that, unambiguously proved that exogenous cytokinins did not have any stimulatory role in tuber growth of potato after induction.

There were significant interactions between sucrose, BAP and photoperiodism on fresh weight of rhizomes as shown in Figure (6) a greatest total rhizome mas was produced from MS medium included $60 \mathrm{~g} / \mathrm{L}$ sucrose and $9 \mathrm{mg} / \mathrm{L}$ BAP under light conditions with significant difference as compared with other treatments.

\section{Rhizomes dry weight (g)}

Overall results showed significant differences between two photoperiodism treatments applied at the 5\% level. However, data in Table (1) revealed that, the highest dry weight of rhizomes had been obtained in cultures incubated under light condition (16-h/day) as compared with that produced under darkness conditions. That pointed to the positive effect of light on accumulation of microrhizomes dry weight of ginger. Our results were in accordance with those reported by $\mathbf{N g ~ ( 1 9 8 8 ) ~ w h o ~ r e p o r t e d ~ t h a t , ~ t h e ~ m o s t ~ f a v o r a b l e ~ d a y ~ l e n g t h ~ f o r ~ t u b e r ~}$ induction was that of 12-h and 16-h day length. Short day length and continuous light were not suitable for tuber induction in tuberization of white yam

Effects of sucrose: sucrose concentrations affected significantly $(\mathrm{P} \leq 0.05)$ among the different treatments (Table 1). Careful observation revealed that, there was a direct relationship between increasing sucrose concentrations and rhizome dry weights in cultures incubated under different photoperiodism. The obtained values of rhizomes dry weights were obtained from cultures treated with 30,60 and $90 \mathrm{~g} / \mathrm{L}$ sucrose giving $0.23,0.64$ and 0.95 , respectively under light conditions. While, incubation under fully darkness condition MS medium supplemented with 30,60 and $90 \mathrm{~g} / \mathrm{L}$ sucrose produced $0.22,0.35$ and $0.65 \mathrm{~g}$ dry weights/jar.

The impact of BAP levels on rhizomes dry weight: most of the obtained results showed significant effect of different concentrations of BAP on dry weight of rhizomes at 5\% level. Data in Table (1) show that, the presence of high concentration of BAP enhanced rhizomes dry weight under 16-h light and the highest value of dry weight $(1.01 \mathrm{~g})$ was recorded with MS medium supplemented with $9 \mathrm{mg} / \mathrm{L}$ BAP. On the contrary to our expectations, the moderate concentration of BAP $(6 \mathrm{mg} / \mathrm{L})$ was more favorable under darkness condition and gave $0.45 \mathrm{~g}$ of rhizomes dry weight/jar. These results were in line with that concluded by Omokolo et al. (2003) who reported that, BAP is well known that exogenous growth regulators control the orientation of soluble carbohydrate flux and thus intervene in the development of tubers. The same authors indicated that, presence of growth regulators in the medium can influence or mask certain physiological and/or biochemical parameters linked to the tuberization of the plant.

In view of the possible interactions between three studied factors (sucrose, BAP and photoperiodism) are shown in Figure (7). The highest value of rhizome dry weight was produced from MS medium contained $90 \mathrm{~g} / \mathrm{L}$ sucrose and $9 \mathrm{mg} / \mathrm{L}$ BAP under light conditions with significant difference comparing with other treatments.

\section{Dry matter content $(\%)$ :}

Results in Table (2) indicate that, sucrose, BAP and photoperiodism had significant effect on percentage of dry matter content at $5 \%$ level. Generally, the effects of photoperiodic regime on dry matter content were evaluated in Table (2). The percentage of dry matter content was higher with rhizomes obtained at darkness conditions as compared to rhizome obtained under light condition. Effects of exposure cultures to light and dark was studied by Dobránszki and Tábori (2010) who cleared that, tuberization of potato was induced by adding an $8 \%$ sucrose solution to 4-week old plantlets and keeping them 2 weeks under short or long days ( 8 and $16 \mathrm{~h} /$ day, respectively) followed by darkness for 9 weeks.

Table 2 Influence of MS medium supplemented with different concentrations of sucrose and BAP on dry matter content (\%), average number of buds/rhizome and average weight of microrhizome (g) of Zingiber officinale after 10 weeks of cultivation under light (L) or darkness (D) conditions at $25 \pm 1^{\circ} \mathrm{C}$

\begin{tabular}{|c|c|c|c|c|c|c|c|c|}
\hline \multirow[t]{2}{*}{ Code } & \multirow[t]{2}{*}{ Sucrose $(g / L)$} & \multirow{2}{*}{$\begin{array}{c}\text { BAP } \\
(\mathbf{m g} / \mathbf{L})\end{array}$} & \multicolumn{2}{|c|}{ Dry matter content $(\%)$} & \multicolumn{2}{|c|}{$\begin{array}{c}\begin{array}{c}\text { Average number of } \\
\text { buds/rhizome }\end{array} \\
\end{array}$} & \multicolumn{2}{|c|}{$\begin{array}{l}\text { Average weight of } \\
\text { microrhizome (g) }\end{array}$} \\
\hline & & & $\mathbf{L}$ & D & $\mathbf{L}$ & D & $\mathbf{L}$ & D \\
\hline HC & \multicolumn{2}{|c|}{ MS basal free sucrose } & 0.00 & 0.00 & 0.00 & 0.00 & 0.00 & 0.00 \\
\hline H1 & 30 & 3 & 6.21 & 10.38 & 1.14 & 1.22 & 0.32 & 0.14 \\
\hline H2 & 30 & 6 & 5.39 & 6.13 & 3.49 & 2.88 & 0.53 & 0.36 \\
\hline H3 & 30 & 9 & 4.96 & 5.02 & 8.65 & 6.63 & 1.74 & 0.76 \\
\hline H4 & 60 & 3 & 9.52 & 12.11 & 3.55 & 3.59 & 0.59 & 0.38 \\
\hline H5 & 60 & 6 & 9.19 & 9.66 & 6.71 & 4.84 & 0.92 & 0.59 \\
\hline H6 & 60 & 9 & 7.79 & 9.43 & 6.65 & 3.02 & 0.95 & 0.34 \\
\hline H7 & 90 & 3 & 17.34 & 16.99 & 3.67 & 3.52 & 0.38 & 0.40 \\
\hline H8 & 90 & 6 & 21.63 & 17.00 & 2.93 & 2.80 & 0.30 & 0.29 \\
\hline H9 & 90 & 9 & 14.00 & 17.76 & 3.38 & 3.09 & 0.47 & 0.35 \\
\hline \multirow{2}{*}{$\mathbf{L S D}_{0.05}$} & & $\mathbf{A}, \mathbf{B}$ & 0.44 & 0.33 & 0.40 & 0.49 & 0.07 & 0.06 \\
\hline & & AB & 0.77 & 0.57 & 0.70 & 0.86 & 0.13 & 0.11 \\
\hline
\end{tabular}

Legend: A - Concentration of sucrose, B - BAP levels, AB - Interaction 


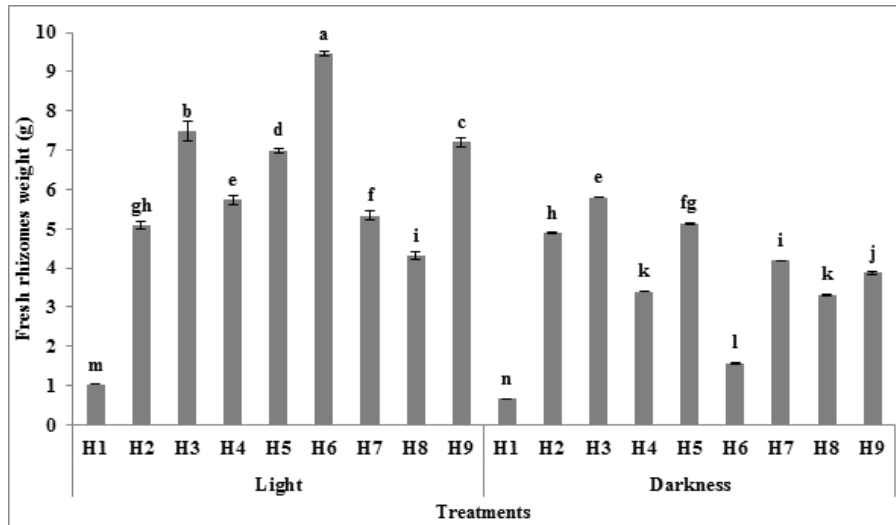

Figure 6 Effect of the interaction between sucrose, BAP and photoperiodism on rhizomes fresh weight $(\mathrm{g})$. Error bars are \pm SE. Treatments that are not significantly different at the 5\% level are indicated by the same letters.

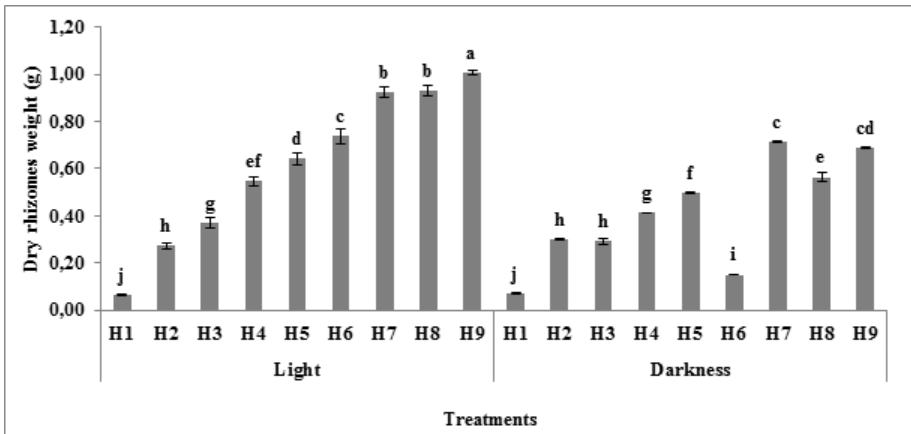

Figure 7 Effect of the interaction between sucrose, BAP and photoperiodism on rhizomes dry weight $(\mathrm{g})$. Error bars are $\pm \mathrm{SE}$. Treatments that are not significantly different at the $5 \%$ level are indicated by the same letters.

Regarding, the effect of sucrose on dry matter content (\%): sucrose concentration in the culture media had a significant effect on dry matter content (\%) as shown in Table (2). Careful observation revealed that, there was a direct relationship between increasing of sucrose concentrations and the percentage of dry matter content. Increase of sucrose concentration in the culture medium increased the dry matter content. A sucrose concentration of $90 \mathrm{~g} / 1$ in the culture medium was considered optimal for accumulation of dry matter content (\%) in rhizomes of ginger under the photoperiod regime. Similarly result was reported by Gamburg et al. (1999) who found that, dry matter content of Jerusalem artichoke microtubers was observed to be unusually high (up to $30 \%$ at $8-10 \%$ sucrose). The effects of the presence of a different concentrations of BAP $(3,6$ and $9 \mathrm{~m} / \mathrm{l})$ on percentage of dry matter content were tested and the obtained results are presented in Table (2). A significant difference can be noted between treatments had different concentrations of BAP. Increasing the BAP concentrations in the medium did not promote the accumulation of dry matter content of rhizomes and high contents of BAP in culture medium caused a significant decrease in dry matter content. The highest percentage of dry matter content $(13.16 \%)$ was recorded MS medium treated with $3 \mathrm{mg} / \mathrm{L}$ BAP under fully darkness conditions. In contrast, the lowest percentage of dry matter contents $(8.91 \%)$ was recorded with $9 \mathrm{mg} / \mathrm{L}$ BAP under light conditions. Moreover, Aksenova et al. (2009) indicate that cytokinins play a dual role in the control of potato tuberization: increased cytokinins content in the leaves and growing potato shoots inhibits tuberization, whereas local enrichment with cytokinins the zones capable of tuber formation stimulates this process.

There were significant interactions between sucrose, BAP and photoperiodism on percentage of dry matter content as presented in Figure (8) the highest percentage of dry matter content was produced from MS medium included $90 \mathrm{~g} / \mathrm{L}$ sucrose and $6 \mathrm{mg} / \mathrm{L}$ BAP under light conditions with significant difference comparing with other treatments.

\section{Average number of buds formation/rhizome}

Average number of buds formation/rhizome was significantly influenced by different photoperiodism. The response of the rhizomes, in terms of average number of buds formed per rhizome, was much greater in cultures incubated under light conditions than those cultures incubated under darkness conditions.

The effects of different concentrations of sucrose on average number of buds/rhizome formation were investigated under fully darkness and $16 \mathrm{~h}$ photoperiod. It was observed that number of buds formed per rhizome significantly changed at the 5\% level between different cultures treated with different concentrations of sucrose. Data in Table (2) show that, the moderate concentrations of sucrose $(60 \mathrm{~g} / \mathrm{L})$ produced the maximum number of buds formed per rhizome under two photoperiods regime.

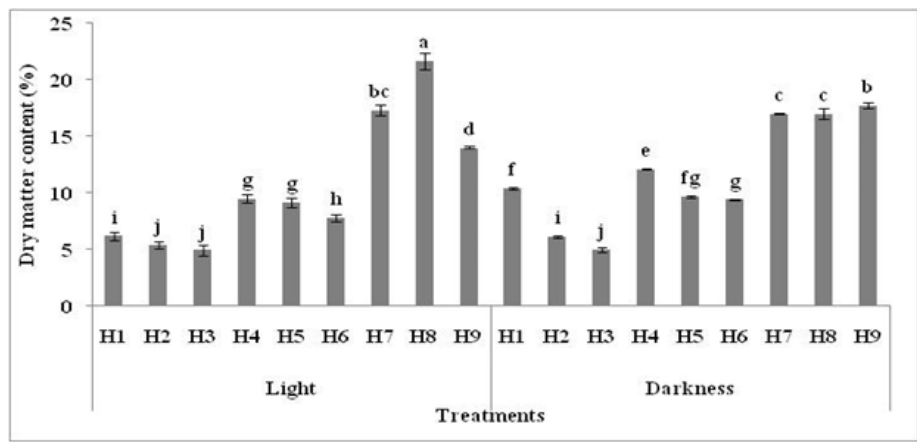

Figure 8 Effect of the interaction between sucrose, BAP and photoperiodism on percentage of dry matter content. Error bars are \pm SE. Treatments that are not significantly different at the $5 \%$ level are indicated by the same letters.

The influences of the presence of a different concentrations of BAP (3, 6 and 9 $\mathrm{m} / \mathrm{l}$ ) on number of buds formed per rhizome were tested and the obtained results are presented in Table (2). A significant difference can be noted between treatments had different concentrations of BAP. A direct relationship between increasing the concentrations of BAP and number of buds formation/rhizome was observed. Similarly, Roy and Banerjee (2002) concluded that, exogenous plant growth regulators were crucial for improved induction and growth rhizomes of Geodorum densiflorum.

The highest number of buds formed per rhizome was recorded with MS medium treated with $3 \mathrm{mg} / \mathrm{L}$ BAP in presence of $30 \mathrm{~g} / \mathrm{L}$ sucrose (Figure 9) with significant difference comparing with other treatments that may be due to previous treatment gave the biggest rhizomes.

\section{Average fresh weight of microrhizome (g)}

Microrhizomes produced under 16-h light/day treatment had a significantly higher average microrhizome fresh weight than those produced in total darkness. However, the effects of different concentration of sucrose on average of microrhizome fresh weight were investigated under fully darkness and 16-h photoperiod. It is evident from the obtained data (Table 2) that, there is a reverse relationship between increasing of sucrose concentrations and average of microrhizome fresh weight under light conditions. While, it seems; from regenerated data that no relationship had been formed between sucrose concentrations and average of microrhizome fresh weight under fully darkness condition. Data also show that, the highest value of microrhizome fresh weight was recorded with 90 and $60 \mathrm{~g} / \mathrm{L}$ of sucrose under light and darkness conditions, respectively. Present results are in agreement with those reported by Chirangini and Sharma (2005) who studied the induction of microrhizome in Zingiber cassumunar and found that, average fresh weight of $(0.81 \mathrm{~g})$ was observed with MS medium supplemented with 5\% sucrose. While, El-Sawy et al. (2007) reported that sucrose was an important factor for micro-tubers formation and the highest tuber formation was achieved when $12 \%$ sucrose was added to culture medium of potato.

The influence of different concentrations of BAP (3, 6 and $9 \mathrm{~m} / \mathrm{l})$ on average fresh weight of microrhizome was tested and the regenerated results are presented in Table (2). Average fresh weight of microrhizome was significantly influenced by adding of exogenous plant growth regulator (BAP). A direct relationship between increasing the concentrations of BAP and average fresh weight of microrhizome was observed under different photoperiodism. This result goes in line with those found by Zhang et al. (2005) who confirmed that, cytokinins including BAP promote cell division, bud formation and stem branching and BAP played a key role for the potato microtuberization. In addition, Ondo Ovono et al. (2010) reported that, polyamine endogenous level and metabolism can be significantly affected by exogenous polyamines, but modifications of endogenous free polyamines could not be directly correlated to the tuber formation process of yam.

In view of the possible interactions between three studied factors are shown in Figure (10). The highest value of rhizome average fresh weight $(\mathrm{g})$ was produced from MS medium contained $30 \mathrm{~g} / \mathrm{L}$ sucrose and $9 \mathrm{mg} / \mathrm{L}$ BAP under light condition with significant difference as compared with other treatments. 


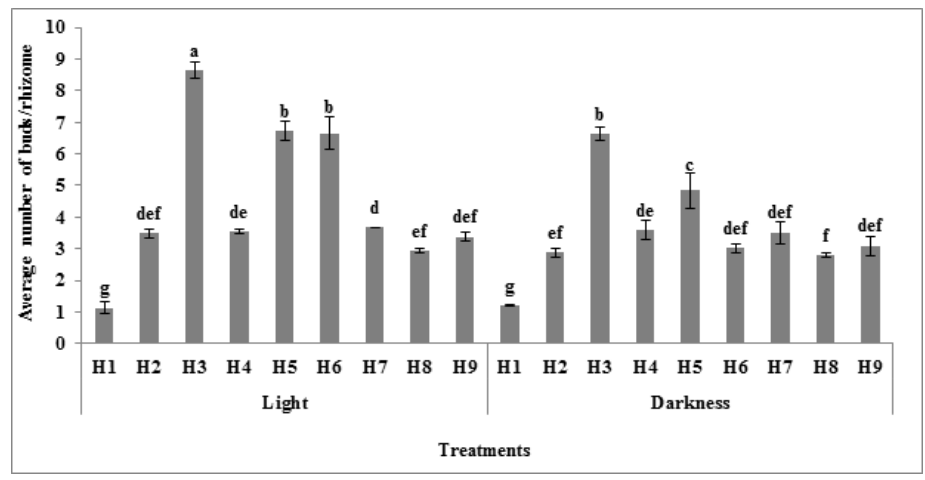

Figure 9 Effect the interaction between sucrose, BAP and photoperiodism on average number of buds formation/rhizome. Error bars are \pm SE. Treatments that are not significantly different at the $5 \%$ level are indicated by the same letters.

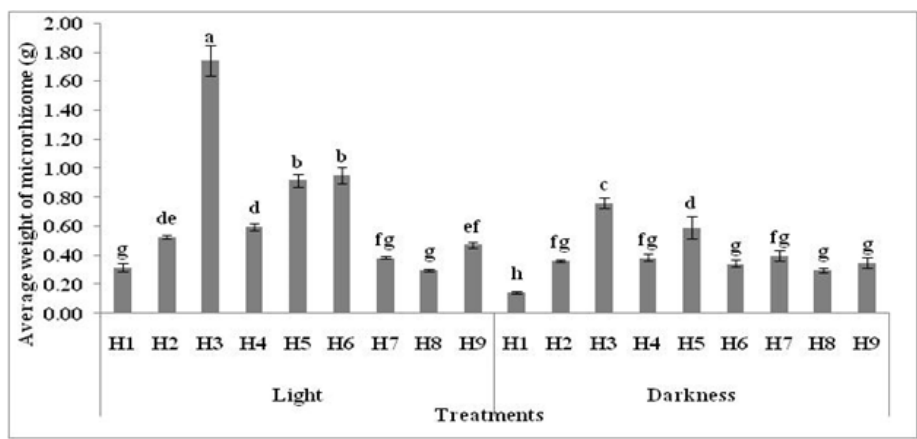

Figure 10 Influence the interaction between sucrose, BAP and photoperiodism on average fresh weight of microrhizome $(\mathrm{g})$. Error bars are \pm SE. Treatments that are not significantly different at the $5 \%$ level are indicated by the same letters.

Regarding, sprouting of rhizomes; the obtained rhizomes derived from differen treatments were planted on multiplication medium (MS $+4.5 \mathrm{~m} / 1 \mathrm{BAP})$ for sprouting, the sprouted shoots were healthy and normal in morphology as shown in Figure (11)

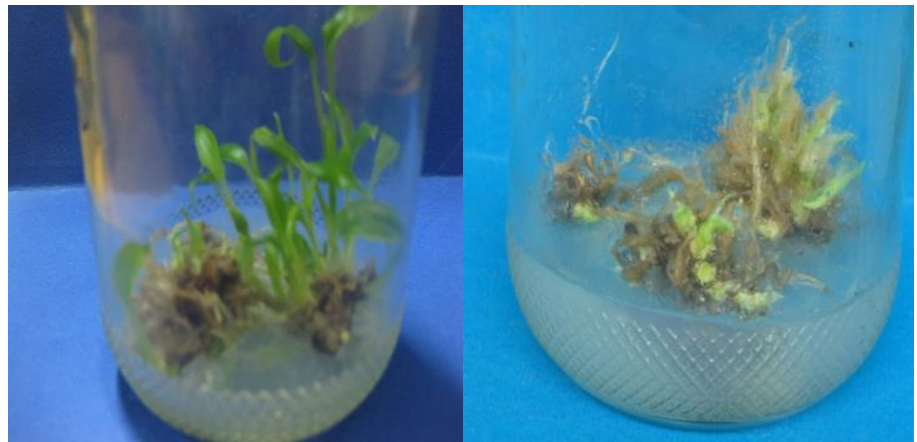

Figure 11 Sprouting in vitro micro-rhizomes of Zingiber officinale growing on MS medium fortified with $4.5 \mathrm{mg} / \mathrm{l} \mathrm{BAP}$ under light conditions at $25 \pm 1{ }^{\circ} \mathrm{C}$.

\section{CONCLUSION}

We can concluded that MS medium supplemented with $9 \mathrm{mg} / \mathrm{L}$ BAP and 60-90 $\mathrm{g} / \mathrm{L}$ sucrose under $16-\mathrm{h}$ photoperiod within 10 weeks of cultivation were the best conditions for ginger microrhizomes induction. However, ginger microrhizomes formation in vitro was found to be controlled by many factors, including the concentrations of BAP and sucrose as well as photoperiodism during culturing period.

\section{REFERENCES}

ABBAS M. S., TAHA, H. S., ALY, U. I., EL-SHABRAWI, H. M. AND GABER, E. I. 2011. Micropropagation of ginger (Zingiber officinale Rosco). Journal of Genetic Engineering and Biotechnology, 9, 2:165-172. http://dx.doi.org/10.1016/j.jgeb.2011.11.002

AKSENOVA, N. P., KONSTANTINOVA, T. N., LOZHNIKOVA, V. N., GOLYANOVSKAYA, S. A. AND SERGEEVA, L. I. 2009. Interaction between day length and phytohormones in the control of potato tuberization in the in vitro culture. Russian Journal of Plant Physiology, 56, 4: 454-461. http://dx.doi.org/10.1134/s1021443709040037

ARCHANA C.P., PILLAI, G. S. AND BALACHANDRAN, I. 2013. In vitro microrhizome induction in three high yielding cultivars of Zingiber officinale rosc. and their phytopathological analysis. International Journal of Advanced Biotechnology and Research, 4 (3):296-300.

BHAT, S. R., CHANDEL, K. P. S. AND KACKAR, A. 1994. In vitro induction of rhizomes in Zingiber officinale Roscoe. Indian Journal of Experimental Biology, 32:340-344.

CHIRANGINI, P. AND SHARMA, G. L. 2005. In vitro propagation and microrhizome induction in Zingiber cassumunar (Roxb.): an antioxidant-rich medicinal plant. International Journal of Food, Agriculture and Environment, 3, 1: 139-142.

CHITHRA, M., MARTIN, K. P., SUNANDAKUMARI, C. AND MADHUSOODANAN, P. V. 2005. Protocol for rapid propagation, and to overcome delayed rhizome formation in field established in vitro derived plantlets of Kaempferia galanga L. Scientia Horticulturae, 104: 113-120. http://dx.doi.org/10.1016/j.scienta.2004.08.014

DAS, P., PALAI, S. K., PATRA, A., SAMANTARAY, S. AND ROUT, G. R. 1999. In vitro somatic embryogenesis in Typhonium trilobatum Schott. Plant Growth Regulation, 27: 193-197.

DOBRÁNSZKI, J. AND TÁBORI, K. M. 2010. Influence of nitrogen supply of potato plantlets on in vitro tuberization pattern under inductive and non-inductive conditions. Potato Research, 53:121-127. http://dx.doi.org/10.1007/s11540-0109156-Z

EBRAHIM, M. K. H. 2004. Comparison, determination and optimizing the conditions required for rhizome and shoot formation, and flowering of in vitro cultured calla explants. Scientia Horticulturae, 101: 305-313. http://dx.doi.org/10.1016/j.scienta.2003.11.002

EL-SAWY, A., BEKHEET, S. AND ALY, U. I. 2007. Morphological and molecular characterization of potato microtubers production on coumarin inducing medium. International Journal of Agriculture \& Biology, 9, 5:675-680. GAMBURG, K. Z., VYSOTSKAYA, E. F. AND GAMANETS, L. V. 1999 Microtuber formation in micropropagated Jerusalem artichoke (Helianthus tuberosus). Plant Cell, Tissue and Organ Culture, 55: 115-118.

GHOSH, S., GHOSH, B. AND JHA, S. 2007. In vitro tuberisation of Gloriosa superba L. on basal medium. Scientia Horticulturae, 114: 220-223. http://dx.doi.org/10.1016/j.scienta.2007.06.008

GOMEZ, K. A AND GOMEZ A. A. 1984. Statistical Procedures for Agricultural Research, Wiley and sons, New York.

GUAN, Q. Z., GUO, Y. H., SUI, X. L., LI, W. AND ZHANG, Z. X. 2008. Changes in photosynthetic capacity and antioxidant enzymatic systems in micropropagated Zingiber officinale plantlets during their acclimation. Photosynthetica, 46, 2: 193-201. http://dx.doi.org/10.1007/s11099-008-0031-y

GUO, Y. AND ZHANG, Z. 2005. Establishment and plant regeneration of somatic embryogenic cell suspension cultures of the Zingiber officinale Rosc $\begin{array}{lll}\text { Scientia } \quad \text { Horticulturae, } & \text { 107: 90-96. }\end{array}$ http://dx.doi.org/10.1016/j.scienta.2005.07.003

GUO, Y., BAI, J. AND ZHANG, Z. 2007. Plant regeneration from embryogenic suspension-derived protoplasts of ginger (Zingiber officinale Rosc.). Plant Cell, Tissue and Organ Culture, 89, 2-3:151-157. http://dx.doi.org/10.1007/s11240007-9223-6

ISLAM, M. A. KLOPPSTECH, K. AND JACOBSEN, H. J. 2004. Population genetic diversity of Curcuma zedoaria (Christm.) Roscoe-a conservation prioritized medicinal plant in Bangladesh. Conservation Genetics, 6:1027-1033. http://dx.doi.org/10.1007/s10592-005-9080-y

JEAN, M. AND CAPPADOCIA, M. 1992. Effects of some growth regulators on in vitro tuberization in Dioscorea alata L. 'Brazo fuerte' and D. abyssinica Hoch. Plant Cell Reports, 11, 1:34-38. http://dx.doi.org/10.1007/bf00231836

JO, E. A., TEWARI, R. K., HAHN, E. J. AND PAEK, K. Y. 2009. In vitro sucrose concentration affects growth and acclimatization of Alocasia amazonica plantlets. Plant Cell, Tissue and Organ Culture, 96:307-315. http://dx.doi.org/10.1007/s11240-008-9488-4

KAPOOR P. AND RAO I. U. 2006. In vitro rhizome induction and plantlet formation from multiple shoots in Bambusa bambos var. gigantea Bennet and Gaur by using growth regulators and sucrose. Plant Cell, Tissue and Organ Culture, 85, 2: 211-217. http://dx.doi.org/10.1007/s11240-005-9074-y

LAUZER, D., LAUBLIN, G., VINCENT, G. AND CAPPADOCIA, M. 1992. In vitro propagation and cytology of wild yams, Dioscorea abyssinica Hoch. and $D$. mangenotiana Midge. Plant Cell, Tissue and Organ Culture, 28, 2: 215-223. http://dx.doi.org/10.1007/bf00055520

MA, X. AND GANG, D. R. 2006. Metabolic profiling of in vitro micropropagated and conventionally greenhouse grown ginger (Zingiber $\begin{array}{llll}\text { officinale }) . & \text { Phytochemistry, } & \text { 2239-2255. }\end{array}$ http://dx.doi.org/10.1016/j.phytochem.2006.07.012

MANTELL, S. H. AND HUGO, S. A. 1989. Effects of photoperiod, mineral medium strength, inorganic ammonium, sucrose and cytokinin on root, shoot and microtuber development in shoot cultures of Dioscorea alata L. and D. bulbifera L. yams. Plant Cell, Tissue and Organ Culture, 16, 1:23-37. http://dx.doi.org/10.1007/bf00044069

MARTIN, K. P. 2003. Clonal propagation, encapsulation and reintroduction of Ipsea Malabarica (Reichb. F.) J. D. Hook., an endangered orchid. In Vitro Cellular and Development Biology - Plant, 39, 3:322-326. http://dx.doi.org/10.1079/ivp2002399 
MEDINA, R. D., FlACHSLAND, E. A., GONZALEZ, A. M. TERADA, G., FALOCI, M. M. AND MROGINSKI, L. A. 2009. In vitro tuberization and plant regeneration from multimodal segment culture of Habenaria bractescens Lindl., an Argentinean wetland orchid. Plant Cell, Tissue and Organ Culture, 97:91101. http://dx.doi.org/10.1007/s11240-009-9505-2

MURASHIGE, T. AND SKOOG, F. 1962. A revised medium for rapid growth and bioassays with tobacco tissue cultures. Physiologia Plantarum, 15: 473-479. http://dx.doi.org/10.1111/j.1399-3054.1962.tb08052.x

NAYAK, S. 2000. In vitro multiplication and microrhizome induction in Curcuma aromatic Salisb. Plant Growth Regulation, 32, 1: 41-47.

NG, S. Y. C. 1988. In vitro tuberization in white yam (Dioscorea rotundata Poir). Plant Cell, Tissue and Organ Culture, 14:121-128. http://dx.doi.org/10.1007/bf00041185

OMOKOLO, N. D., BOUDJEKO, T. AND TAKADONG, J. J. T. 2003. In vitro tuberization of Xanthosoma sagittifolium L. Schott: effects of phytohormones, sucrose, nitrogen and photoperiod. Scientia Horticulturae, 98:337-345. http://dx.doi.org/10.1016/s0304-4238(03)00066-9

ONDO OVONO, P., KEVERS, C. AND DOMMES, J. 2009. Effects of reducing sugar concentration on in vitro tuber formation and sprouting in yam (Dioscorea cayenensis - D. rotundata complex). Plant Cell, Tissue and Organ Culture, 99, 1:55-59. http://dx.doi.org/10.1007/s11240-009-9575-1

PRUSKI, K., ASTATKIE, T. AND NOWAK, J. 2002. Jasmonate effects on in vitro tuberization and tuber bulking in two potato cultivars (Solanum tuberosum L.) under different media and photoperiod conditions. In Vitro Cellular and Development Biology - $\quad$ Plant, $38, \quad 2: 203-209$. http://dx.doi.org/10.1079/ivpivp2001265

ROH, K. H., IUM, T. S., LEE, J. H. CHOI, I. L., CHOI, Y. H. AND JANG, Y. S. 1996. In Vitro propagation and tuberization of plantlet regenerated from shoot-tip culture in ginger. Korean J. Plant Tissue Culture, 23, 3: 129-134.

ROUT, G. R., PALAI, S. K., SAMANTARAY, S. AND DAS, P. 2001. Effect of growth regulator and culture conditions on shoot multiplication and rhizome formation in ginger (Zingiber officinale Rosc.) in vitro. In Vitro Cellular and Development Biology - Plant, 37, 6:814-819. http://dx.doi.org/10.1007/s11627001-0135-6

ROY, J. AND BANERJEE, N. 2002. Rhizome and shoot development during in vitro propagation of Geodorum densiflorum (Lam.) Schltr. Scientia Horticulturae, 94: 181-192. http://dx.doi.org/10.1016/s0304-4238(01)00373-9

SARKAR, D., PANDEY, S. K. AND SHARMA, S. 2006. Cytokinins antagonize the jasmonates action on the regulation of potato (Solanum tuberosum) tuber formation in vitro. Plant Cell, Tissue and Organ Culture, 87, 3:285-295. http://dx.doi.org/10.1007/s11240-006-9166-3

SHARMA, T. R. AND SINGH, B. M. 1995. In vitro microrhizome production in Zingiber officinale Rosc. Plant Cell Rep., 15: 274-277. http://dx.doi.org/10.1007/bf00193735

SHIRGURKAR, M. V., JOHN, C. K. AND NADGAUDA, R. S. 2001. Factors affecting in vitro microrhizome production in turmeric. Plant Cell, Tissue and Organ Culture, 64: 5-11.

SLIMMON, T., MACHADO, V. S. AND COFFIN, R. 1989. The effect of light on in vitro microtuberization of potato cultivars. American Potato Journal, 44: 843-848. http://dx.doi.org/10.1007/bf02853965

TYAGI, R. K., AGRAWAL, A. YUSUF, A. 2006. Conservation of Zingiber germplasm through in vitro rhizome formation. Scientia Horticulturae, 108 210-219. http://dx.doi.org/10.1016/j.scienta.2006.01.018

ZHANG, Z., ZHOU, W. AND LI, H. 2005. The role of GA, IAA and BAP in the regulation of in vitro shoot growth and microtuberization in potato. Acta Physiologiae Plantarum, 27, 3B: 363-369. http://dx.doi.org/10.1007/s11738-0050013-7

ZHENG, Y., LIU, Y., MA, M. AND XU, K. 2008. Increasing in vitro microrhizome production of ginger (Zingiber officinale Roscoe). Acta Physiologiae Plantarum, 30:513-519. http://dx.doi.org/10.1007/s11738-008$\underline{0149-3}$ 